\title{
INOVAÇÃO NO MERCADO DE PET SHOPS
}

\section{Bruna Rodrigues Lima}

Bacharel em administração pela Universidade Presbiteriana Mackenzie. bru_borona@hotmail.com (Brasil)

\section{Fernanda Rodrigues lima}

Bacharel em administração pela Universidade Presbiteriana Mackenzie. fe_tata@hotmail.com (Brasil)

\section{Gabriel Barbieri}

Bacharel em administração pela Universidade Presbiteriana Mackenzie. g_lbg@hotmail.com (Brasil)

\section{Luciano Augusto Toledo}

Doutor em administração pela FEA-USP.

Professor Adjunto da Universidade Presbiteriana Mackenzie luciano@makenzie.br (Brasil)

\section{RESUMO}

$\mathrm{O}$ artigo tem por o objetivo colocar em relevo alguns aspectos relacionados a inovação que podem ser influenciadores no processo de compra no mercado de Pet Shops no Brasil. O trabalho faz uso da metodologia qualitativa com base no tratamento de dados do discurso do sujeito coletivo (DSC). Dessa forma são apresentados 12 temas discursivos que ilustram os aspectos mais relevantes e citados pelos entrevistados. Finalmente a análise do discurso contribuiu com três diferentes representações sociais que a inovação pode assumir no mercado de Pet Shop pode sob a perspectiva dos consumidores.

Palavras-chaves: Pet Shop; Inovação; DSC. 


\section{INTRODUÇÃO}

O mercado de produtos Pets no Brasil, a despeito de relativamente contemporâneo, dá sinais de que, dentro em breve, estará próximo de conseguir o sucesso obtido em outras regiões do planeta e sinais para isso não faltam: além do fato de humanização dos animais de estimação, observa-se que a sua população cresce proporcionalmente ao número de pessoas no. Certo que, diante dessa realidade, quem mais ganha com a soma desses fatores são os chamados pet shops - lojas especializadas em proporcionar produtos e serviços para animais domésticos de pequeno e médio porte. Para se ter uma ideia da relevância que esse setor vem ganhando nos últimos tempos na economia do País, basta conferir que, desde 95, o mercado cresce a uma média anual de 17\%, faturando cerca de US\$ 1,5 bilhão ao ano. O que, a princípio, é surpreendente ganha fundamento quando se analisa que tal segmento atende a uma "população" de cerca de 25 milhões de cães, 11 milhões de gatos, 4 milhões de pássaros e, ainda, 500 mil aquários espalhados por todo o Brasil segundo dados da Associação de Produtos e Prestadores de Serviços ao Animal (ASSOFAUNA). Mesmo existindo hoje, perto, cerca de 9 mil pet shops no Brasil, especialistas acreditam que a oferta de produtos e serviços cresce a uma velocidade muito maior do que o avanço do próprio mercado. A explicação para isso, afirmam, está no fato de que, como mostrou ter potencial com seu ritmo de crescimento acelerado, o setor viu surgir, além de novos modelos de lojas, diversos canais de distribuição - todos inquietados com sua participação nessa evolução. Diante disso, observa-se um descompasso entre o perfil do consumidor e sua expectativa frente às lojas existentes - dando margens a entrada, no mercado, de conceitos, ações e estratégias de marketing visando novos formatos de relacionamento e/ou diferenciais na comercialização de produtos ou na oferta de serviços. Ao mesmo tempo em que estimam alcançar um volume de negócios, este ano de 2013, em torno de R \$ 14 bilhões, empresários do setor sabem que 2014 será o período de consolidação das mudanças provenientes de um longo processo de ajustes por qual passa o mercado de pet shops no Brasil desde meados de 95.

Com a profissionalização do varejo particularizado e a chegada das megalojas, as empresas do segmento passaram a procurar modos alternativos para alargamento de suas marcas e negócios. Funcionamento 24 horas por dia, disponibilização de pessoal especializado e devidamente treinado no atendimento dos bichos e de seus donos e reformulação do seu composto de produtos são algumas das estratégias utilizadas por muitos pet shops na busca por um diferencial competitivo, podendo esse estar alicerçado em conceitos de inovação.

Revista de Administração e Inovação, São Paulo, v. 10, n.1, p. 06-26, Jan./Mar. 2013. 


\section{PROBLEMA DE PESQUISA}

Quais aspectos inovativos são influenciadores no processo de compra no mercado de Pet Shops?

\section{OBJETIVO GERAL}

Apurar no mercado de Pet Shops os aspectos influenciadores no processo de compra.

\subsection{OBJETIVOS ESPECÍFICOS}

Apontar alguns aspectos inerentes à inovação;

Elencar peculiaridades do comportamento de compra;

Colocar em relevo a atual situação do mercado de Pet Shops no Brasil.

\section{METODOLOGIA}

O escopo geral do método de pesquisa é descobrir respostas ou soluções aos problemas por meio de uma investigação organizada, crítica, metódica, científica e baseada em dados analisados (DEMO, 1995; FIELDING, 1999). Um método é um conjugado de processos pelos quais se torna possível sopesarem um específico fenômeno. Distingue-se, ainda, pela preferência de procedimentos sistemáticos para descrição e esclarecimento de uma determinada situação a ser estudada (COLLIS; HUSSEY, 2010). Dentro do método científico pode-se optar por abordagens quantitativas ou qualitativas, ainda que haja autores que desacertem desta dicotomia. As abordagens quantitativas descritivas e inferenciais quando necessárias preocupam-se com quantificação de dados, aproveitando-se para isto de recursos e técnicas estatísticas (COLLIS; HUSSEY, 2010; TRIVINOS, 1997). A abordagem qualitativa tem sido frequentemente utilizada em estudos voltados para a compreensão da vida humana em conjugados, em campos como sociologia, antropologia, psicologia, dentre outros das ciências sociais. Na descrição do método deve-se evidenciar como será executada a pesquisa e o desenho do método que se pretende adotar: será do tipo quantitativo, qualitativo, descritivo, explicativo ou exploratório? Será um levantamento, um estudo de caso, uma 
pesquisa experimental, um ensaio etc.? (DEMO, 1995; SEVERINO, 2008). Para esse trabalho conjecturou-se o uso da metodologia qualitativa denominada Teoria do Discurso do Sujeito Coletivo. Esta teoria propõe a utilização de quatro figuras metodológicas para ajudar a organizar depoimentos e demais discursos. São elas: a ancoragem, a ideia central, as expressões-chave e o discurso do sujeito coletivo (DSC) (LEFEVRE; LEFEVRE, 2006). Para efeito de análise dos depoimentos, a ideia Central pode ser entendida como a síntese do conteúdo discursivo explicitado pelos sujeitos. São as afirmações, negações e dúvidas a respeito da realidade baseada em fatos, bem como os juízos de valor a respeito da realidade institucional e do contexto onde os sujeitos estão envolvidos (LEFEVRE, F.; LEFEVRE, A. M. C., 2006). Relata-se que e o discurso do sujeito coletivo consiste em uma estratégia metodológica que objetiva tornar mais claro uma dada representação social. É a reunião, em um só discurso-síntese, de vários discursos individuais emitidos como resposta a uma mesma questão de pesquisa demandada por sujeitos social que fazem parte de uma mesma cultura organizacional ou grupo (LEFEVRE; LEFEVRE, 2006). Por fim o DSC é uma forma de expressar diretamente a representação social de um determinado sujeito social. Para a coleta de dados foi utilizada a entrevista não estruturada aplicada em uma amostra não probabilística constituída por clientes de empresas do segmento Pets, totalizando uma amostra não probabilística de 53 compradores. Tal escolha deveu-se ao fato de que a metodologia do DSC representa um discurso síntese elaborada com pedaços de discursos. Consiste ainda, em uma técnica de tabulação e organização de dados qualitativos que resolve um dos grandes impasses da pesquisa qualitativa na medida em que permite, por meio de procedimentos sistemáticos e padronizados, agregar depoimentos sem reduzi-los a quantidades (LEFEVRE; LEFEVRE, 2006).

\section{REFERENCIAL TEÓRICO}

\subsection{PECULIARIDADES CONCEITUAIS DE INOVAÇÃO}

Nota-se que grande parte das corporações já percebe a necessidade de criar inovações e por isso buscam-nas de forma sistemática, pois sabem que as mesmas podem lhes conferir um importante fator para se mantiver nesses mercados concorridos, fato que gera vantagem competitiva (AFUAH, 2009; OLIVA et al., 2011). Isso só é possível, pois as inovações carregam consigo aprendizado e alavancagem tecnológica. Por acreditar que os empreendedores devem buscar inovações sistemáticas dentro das organizações e serem criados processos organizados com a

Revista de Administração e Inovação, São Paulo, v. 10, n.1, p. 06-26, Jan./Mar. 2013. 
finalidade de obter essas inovações nas empresas. Ainda a partir do momento em que diversos tipos de aprendizado estão presentes em uma companhia, a junção de todos eles pode gerar uma inovação (DRUCKER, 2008; ROBERTSON, 1967). Já no processo de inovação existem aspectos a serem considerados em cada etapa para facilitar o filtro das ideias. Na figura 1 abaixo se pode observar detalhadamente os filtros para cada etapa (BESSANT; TIDD, 2007).

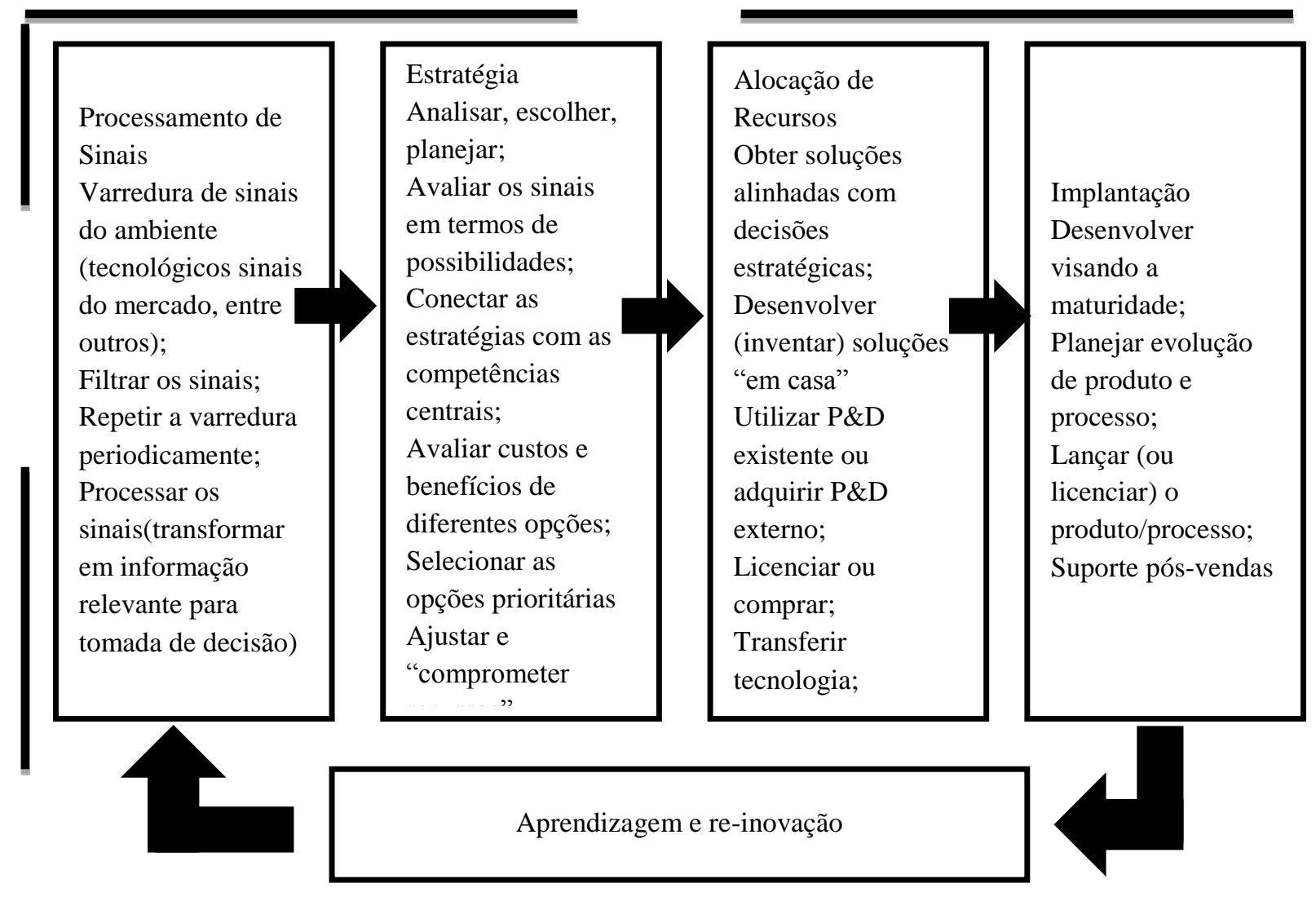

Figura 1: Filtros de ideias

Fonte: Tidd et. al. (2007).

De acordo com o quadro, se observa que nas primeiras etapas o volume de ideias é maior, no decorrer do processo diferentes critérios que são utilizados para filtrar as ideias vão reduzindo esse volume até chegarem a um volume muito menor, restando somente as ideias realmente factíveis para a organização, conceito similar aos apresentados anteriormente. Para poder realizar corretamente o filtro de ideias, as empresas também precisam entender os tipos de inovações que o mercado percebe atualmente e como essas inovações podem ser entendidas pelos consumidores. Tendo definido o tipo de inovação e como ela é percebida, o processo pode se tornar mais eficaz (BESSANT; TIDD, 2007). 
Em relação ao processo de inovação diante dessa necessidade de inovar, as empresas devem alterar suas estruturas, culturas e processos. Para, assim, adequarem e criarem um ambiente favorável à inovação (MARKIDES, 2006). Entretanto outros aspectos podem ser considerados relevantes. É imprescindível que se tenha baixo nível de formalização, utilização de formas avançadas de departamentalização, múltiplos comandos, comunicação bem desenvolvida horizontal e diagonalmente. As inovações devem primeiramente ser aceitas pelo topo da pirâmide das empresas para que todos os colaboradores divulguem as novas ideias (KRISHNAN; PRAHALAD, 2010). Todos esses aspectos funcionando juntos podem ser excelentes catalisadores dentro do processo de inovação. Essa troca de ideias pode gerar um grande aprendizado internamente e a intenção é que esse aprendizado fique registrado nos sistemas da empresa, possibilitando desta forma a geração de uma rede de conhecimento interna, o que facilita a mensuração do tamanho do capital intelectual da organização (DRUCKER, 2008). A empresa deve, além disso, dar liberdade de iniciativa, estimular a criatividade e recompensar os esforços e as ideias inovadoras provenientes de seus funcionários. Finalmente, para que todos esses fatores possam fluir com facilidade por todas as camadas da empresa, não devem existir bloqueios no fluxo de informações e comunicação dentro desse processo (CHESBROUGH, 2007). Dessa forma, as empresas tendem a aumentar suas chances de criar inovações internamente, seus funcionários ficam mais motivados, há diminuição significativa dos níveis de rotatividade e ainda pode melhorar sua imagem no mercado, o que consequentemente poderá atrair novos talentos para a organização. Retomando alguns pontos importantes em relação à inovação: a empresa deve compreender o conceito, qual a sua importância, como criar um processo adequado, como criar um ambiente que favoreça sua criação e disseminação internamente. Além de precisar compreender em qual categoria essa inovação se encaixará e como fazer para que ela seja percebida de acordo com seu tipo e grau (KRISHNAN; PRAHALAD, 2010).

São utilizadas quatro categorias abrangentes para definir os tipos de inovação (BESSANT; TIDD, 2007): Inovação de produto: modificações nos produtos e serviços de uma empresa; Inovação de processo: modificações na forma como esses produtos e serviços são criadas e oferecidas aos consumidores; Inovação de posição: modificações no contexto em que os produtos e serviços são introduzidos; Inovação de paradigma: alterações nos modelos mentais que não se manifestam, mas estão ocultos ou subentendidos e orientam as ações da empresa. É possível ainda dividir os tipos de inovação de uma maneira mais abrangente se comparado à definição dos autores contemporâneos. Os tipos de inovação na visão desse autor são: Introdução de novos produtos, ou 
novas qualidades de um bem; Introdução de novos métodos de produção, ou seja, um novo método que ainda não tenha sido testado, que não precisa estar vinculado a uma nova descoberta científica necessariamente (SCHUMPETER, 2000). Pode constituir também uma maneira nova de distribuição comercial da mercadoria; Abertura de novos mercados; Desenvolvimento de novas fontes provedoras de matérias-primas e outros insumos, independentemente se essas fontes já existiam ou tiveram que ser criadas; Criação de novas estruturas de mercado em uma indústria, estabelecimento de nova organização para o negócio (SCHUMPETER, 2000).

Para completar o estudo sobre inovação há um último conceito importante, que é o modelo de adoção de inovação, ou seja, quais são critérios ou fatores que os consumidores levam em consideração no momento de adotar uma inovação (ROGERS, 1995). Nesse modelo a taxa de adoção é a velocidade relativa com que uma inovação é adotada por membros de um sistema social. Conforme o autor, adoção é o momento em que o consumidor decide utilizar a inovação e posteriormente ocorrerá a difusão, ou seja, a comunicação da existência da inovação para outras pessoas por meio de diferentes canais durante um período de tempo (ROGERS, 1995). A palavra chave para definir difusão é a comunicação, ou seja, como essa inovação será difundida para os diversos tipos de consumidores do mercado a partir do momento em que ela for percebida pelo individuo (ROGERS, 1995). Isso pode acontecer dentro ou fora das empresas. Mas como saber de que forma as inovações são percebidas pelos consumidores? O que os faz adotarem novos serviços? Segundo a percepção dos indivíduos, as características necessárias às inovações são (ROGERS, 1995):

-Vantagem Relativa: constitui o grau no qual se percebe a inovação como algo melhor que a ideia que a precede;

- Compatibilidade: grau no qual se identifica a inovação como consistente com os valores prevalecentes e experiências passadas dos perceptores;

- Complexidade: grau no qual uma inovação é relativamente fácil ou difícil de entender;

- Praticabilidade: grau no qual uma inovação pode ser experimentada;

- Observabilidade: grau no qual os resultados de uma inovação são visíveis para outros indivíduos.

Há outros modelos de adoção que corroboram o modelo de Rogers (1995), tal qual o modelo que considera os aspectos mais importantes das inovações para que elas sejam adotadas são as 
características da organização, o ambiente externo e os atributos da inovação e fornecedores (FRAMBACH; SCHILLEWAERT, 2002).

Dentro de cada um desses aspectos eles destacam as características que devem aparecer nas inovações, conforme Figura 2 abaixo:

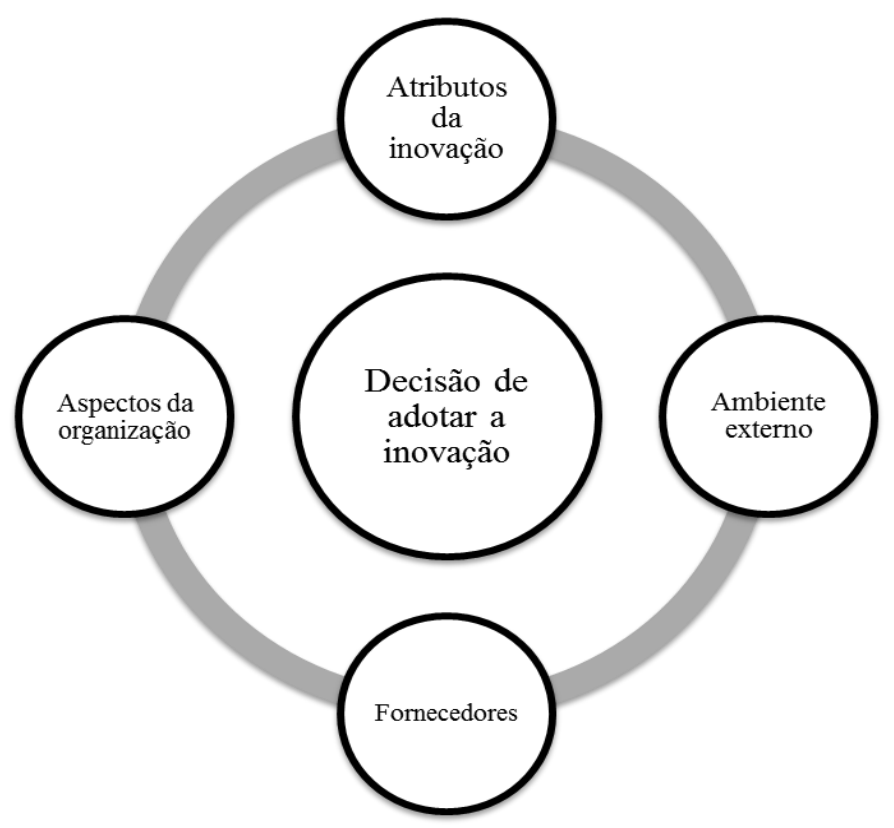

Figura 2 - Características Inovativas

Fonte: Frambach; Schillewaert (2002).

Nesse modelo existem aspectos a serem analisados, não basta apenas que a inovação seja adotada pelo mercado. Com a aplicação desses critérios fica mais fácil de as organizações filtrarem as ideias dentro do processo de inovação e verificarem o que realmente é viável ou não, tomando decisões com embasamento empírico (TOLEDO; ZILBER, 2009). É de extrema importância a aplicação desses conceitos dentro do segmento em que a empresa atua para que fique claro qual o tipo de inovação criado para aquele mercado (FRAMBACH; SCHILLEWAERT, 2002; TOLEDO; ZILBER, 2012).

\subsection{TEORIA DA COMPRA}

O comportamento do consumidor é definido como as atividades de obtenção, consumo e disposição, além do processo de decisão que envolve essas atividades (VARGAS, 2008). Seguindo 
a mesma linha de raciocínio o comportamento do consumidor constitui estudo dos processos de aquisição, consumo e a disposição de mercadorias, serviços, experiências e ideias (KOTLER; KELLER, 2009). Da mesma maneira comportamento do consumidor abrange os processos de relacionamento dos grupos a fim de satisfazer suas necessidades por meio da compra e consumo de serviços, ideias ou experiências (SHETH et al., 2001). É definido, ainda, que comportamento do consumidor como atividades físicas e mentais realizadas pelos consumidores que resultam em decisões de como adquirir produtos e serviços, além de avaliar a maneira de pagar por eles (SHETH et al., 2001). Pode-se observar mediante as definições apresentadas que o comportamento do consumidor nada mais é do que o estudo dos processos de aquisição e consumo de bens e serviços, além dos processos de decisão que envolve essas ações. Podem ser consideradas também as trocas de ideias e experiências entre compradores e fornecedores (SHETH et al., 2001).

Esse tema pode ser visto por diferentes perspectivas. A primeira delas é a influência do consumidor. Nesse caso o comportamento do consumidor é de interesse daqueles que desejam influenciá-lo: organizações e áreas de marketing estão entre os maiores interessados (KOTLER; KELLER, 2009). Nesse sentido, os autores descrevem o processo de planejar e executar a concepção, o preço, a promoção e a distribuição das ideias, mercadorias e serviços a fỉm de satisfazer as necessidades dos consumidores. A chave desta definição é a troca entre consumidores e fornecedores, na qual cada parte entrega algo de valor ao outro, fazendo com que ambas as partes ganhem (PETER et al., 1993). A segunda perspectiva é a educação e proteção do consumidor, na qual existem outras pessoas que também querem influenciar o comportamento do consumidor, mas o fazem com a intenção de contribuir e auxiliar a compra de maneira racional. Por meio da educação, o consumidor pode ser ensinado a detectar a presença de abusos por parte das organizações. E por último as políticas públicas, as quais são importantes para a definição de leis e ações para inibir a produção de campanhas abusivas, já que o processo de educação por si só não é suficiente para fazer com que não existam abusos comerciais (PETER et al., 1993).

Há a proposta de não se dividir a visão desse assunto em diferentes perspectivas, mas classifica os estágios de consumo no processo de troca (SOLOMON, 1987). Assim é descrito que os critérios utilizados para avaliar produtos e serviços em um papel podem ser bem diferentes dos utilizados em outro. Afirma também que em seus estágios iniciais de desenvolvimento, o tema era chamado de comportamento do comprador, o que enfatizava a interação entre consumidores e produtores no momento da compra (SOLOMON, 1987). Grande parte dos profissionais de marketing reconhece que o comportamento do consumidor é um processo contínuo, ou seja, que não 
ocorre somente no instante em que um consumidor entrega um valor em troca de algo para satisfazer suas necessidades. Relata ainda a importância de conhecer os consumidores para a segmentação de mercado das empresas. Neste caso nota-se um direcionamento da importância do estudo do comportamento do consumidor para o sucesso organizacional, isso porque as empresas que estiverem à frente na compreensão dos perfis de seus consumidores possuem grandes chances de sucesso, destacando-se de seus concorrentes (SOLOMON, 1987).

Verifica-se então que o estudo do comportamento do consumidor teve como interessados iniciais os profissionais de marketing, que buscavam conhecer melhor o seu cliente a fim de aplicar suas estratégias de influência. No entanto, profissionais de outras áreas também passaram a se interessar pelo assunto com o intuito de melhor compreender as relações humanas presentes nos processos de interação entre os consumidores e as organizações. Além de analisar os agentes de educação e capacitação dos consumidores, incentivando a constante existência da ética nas ofertas das empresas, instruindo as compras racionais, sensatas e sem abusos (PETER et al., 1993).

Existem muitas decisões inter-relacionadas tomadas diariamente pelos consumidores. A opção de compra pode ser considerada uma das decisões do consumidor, neste item ele avalia se deve comprar ou economizar, quando comprar e o que comprar. Considerando a categoria de produto, a sua marca, onde comprar e como irá pagar (SOLOMON, 1987). Outra decisão é a opção de consumo, baseada nela o consumidor analisa se deve ou não consumir, quando e como consumir. A última decisão engloba as opções de despojamento, nesta o cliente em potencial avalia o descarte sumário, reciclagem e o remarketing, que é conceituado pelo autor como a revenda de itens usados. De maneira similar se define que os consumidores possuem uma estratégia de tomada de decisão. Após a identificação da necessidade, ocorre uma avaliação do esforço exigido comparado ao retorno que a decisão trará (SOLOMON, 1987).

Já o processo de tomada de decisão de compra do consumidor segue os estágios de reconhecimento de necessidade, que é aquele em que o processo decisório é ativado; a busca de informação, na qual o consumidor busca no mercado os dados que o auxiliam na tomada de decisão; a avaliação de alternativa pré-compra, que é a analise das opções e a escolha; a compra, que nada mais é do que a aquisição do bem; o consumo, que é classificado pelos autores como o uso da alternativa escolhida e por fim, a avaliação da pós-compra, que é a mensuração do grau de satisfação do consumidor após o consumo do produto (HENRIQUES, 2010; SHAPIRO, 1985; VARGAS, 2008). Deste modo, muitos fatores podem influenciar no processo de tomada de decisão dos consumidores, desde questões sociais, ações de marketing e até o nível de esforço que o 
consumidor terá que demandar para a aquisição desejada. Pôde-se observar que além das decisões baseadas nos fatores internos e externos, a tomada de decisão de compra segue estágios que se mostram interligados, seguindo um fluxo de ações e reações (YOON, 2002), segue: reconhecimento de uma necessidade por parte do consumidor; busca de informações sobre sua necessidade; alternativas disponíveis para saná-la; avaliação dos pontos relevante; e, finalmente a realização da compra. Essa compra fará com que o produto seja experimentado, havendo então nova análise e conclusão dos resultados obtidos em relação à necessidade levantada no início do processo.

\section{RESULTADO DA PESQUISA}

\subsection{MERCADO DE PET SHOPS NO BRASIL}

De olho no crescimento acelerado do mercado mundial de produtos pet, que movimenta cerca de US\$ 73 bilhões por ano, a ordem é ser criativo. Pet shops inovam com produtos diferenciados, como esmaltes e refrigerantes, salões de beleza para animais oferecem novos tipos de banhos, tosas e secagem de pelos, com produtos importados de alto nível e serviços de entrega. Os estabelecimentos faturam até $\mathrm{R} \$ 200$ mil por mês. O Brasil tem hoje o segundo maior mercado pet do mundo, perdendo apenas para os Estados Unidos (RIGUEIRA, 2012). Segundo dados da Associação Nacional de Fabricantes de Produtos para Animais de Estimação (ANFALPET), o Brasil tem estrutura e capacidade de produção para ser também o segundo maior exportador de artigos do segmento, com US\$ 4 bilhões ao ano. O potencial de exportação dos produtos é de US\$ 15 bilhões - no ano de 2012, ficou em US\$ 250 milhões, ou seja, ainda falta muito para alcançar o potencial. Também 2012, o mercado brasileiro movimentou R \$ 9,6 bilhões e a estimativa da ANFALPET é que apresente um crescimento de até 5\% este ano (RIGUEIRA, 2012).

\subsection{Análise do Discurso}

Foram realizadas entrevistas individuais, baseadas em técnicas do método qualitativo do Discurso do Sujeito Coletivo (DSC). As ideias centrais dessas entrevistas foram destacadas, categorizadas e consolidadas em discursos únicos, conforme descrito anteriormente (LEFEVRE;

Revista de Administração e Inovação, São Paulo, v. 10, n.1, p. 06-26, Jan./Mar. 2013. 
LEFEVRE, 2006). A formulação desses discursos possibilitou o destaque de doze ideias centrais, apresentadas a seguir:

- Discurso 1 - Bem estar do animal: as pessoas adquirem serviços que proporcionam higiene e saúde; que supram todas as necessidades dos animais; e que promovam sua socialização, tirando-os do ambiente comum, fato que os deixa mais calmos. Os animais recebem tratamento diferenciado, mas há a consciência de que certos limites devem ser respeitados. Há indícios de que o foco está sempre no bem estar e alegria dos animais.

- Discurso 2 - Entretenimento pessoal: O Pet Shop também é visto como um espaço de lazer para proprietários de animais, lugar onde é possível trocar experiências com outras pessoas. Além disso, verifica-se que a visita ao estabelecimento estimula o consumo.

-Discurso 3 - Comodidade dos clientes: os consumidores apontam a facilidade de encontrar em um mesmo local todos os serviços necessários para cuidar de seus animais como um dos maiores atrativos dos Pet Shops, serviços estes avaliados como difíceis de executar em casa. Outra característica apontada como relevante é a proximidade desses estabelecimentos com a residência dos clientes, além da acessibilidade do local, já que todos os entrevistados vivem em São Paulo onde o trânsito é considerado fator crítico.

- Discurso 4 - Confiança e segurança dos consumidores: os consumidores discorrem sobre a importância de conhecer o ambiente físico e os profissionais do Pet Shop que escolheram para cuidar dos seus animais. A percepção de que os prestadores de serviço amam suas profissões cativa os consumidores, que procuram novamente o estabelecimento. A fidelidade a um mesmo Pet Shop foi apontada como fator facilitador da relação entre os prestadores de serviço e os animais, os depoimentos demonstram que a junção dos fatores citados aliada à marca de um estabelecimento conhecido no mercado resulta em maior confiança, os consumidores sentem-se mais seguros.

- Discurso 5 - Animal é visto como membro da família: Os depoimentos coletados demonstram que os animais de estimação são considerados membros da família, isso faz com que os consumidores procurem sempre os melhores serviços disponíveis, independente de preço, a intenção é sempre melhorar a qualidade de vida dos seus animais. Pode-se fazer uma analogia com a relação entre pais e filhos, pois há relatos de demonstração de carinho entre ambas as partes, pessoas e animais.

- Discurso 6 - Troca por percepção de vantagem: Os consumidores comparam os benefícios oferecidos pelos serviços habituais com as vantagens dos serviços novos. Caso a novidade 
seja percebida como mais vantajosa, ganhará relevância e poderá refletir na troca de serviço. Outro ponto importante é a superação das expectativas dos consumidores, eles querem ser surpreendidos.

- Discurso 7 - Experimentação: Quando se trata de serviços novos, nota-se que os entrevistados avaliam a possibilidade de testar a inovação, mensurar seus resultados e se positivos, adquirir o serviço novamente.

- Discurso 8 - Preço: Uma das variáveis utilizadas para decisão de compra nesse mercado é o preço, os depoimentos demonstram que os consumidores realizam comparações entre os Pet Shops e percebem que as grandes redes ainda oferecem preços menores. Os serviços novos e diferenciados são em sua maioria bem vistos, porém a maioria não consome porque o preço é considerado muito alto. Em paralelo, observa-se que os consumidores fazem questão da qualidade nos serviços prestados, o que demonstra que o aumento de preço para manutenção da qualidade não gera rejeição por parte dos clientes.

- Discurso 9 - Satisfação advinda do atendimento: Desde os mais básicos e corriqueiros, os serviços prestados nos Pet Shops devem atender todos os requisitos considerados essenciais para os consumidores. Os depoimentos demonstram que os consumidores desejam um atendimento especializado, que respeite as peculiaridades de seu animal e que cumpra os prazos pré-estabelecidos de execução dos mesmos. Verifica-se que nesse mercado os clientes valorizam o bom atendimento em todos os estágios da prestação de serviços, que vai desde a recepção até o pós-venda.

- Discurso 10 - Quantidade de inovações percebidas: O constante surgimento de novidades e a existência de serviços diferenciados são pontos considerados importantes nos Pet Shops. Locais que não oferecem novidades tornam-se desinteressantes.

- Discurso 11 - Qualidade: A percepção de qualidade está associada à entrega de serviços que proporcionem o bem estar dos animais, além disso, os entrevistados apontaram a funcionalidade como fator complementar. Os relatos indicam que quando um serviço é considerado de qualidade, os consumidores parecem não se importar com o valor desembolsado e direcionam a atenção para os atributos dos serviços.

- Discurso 12 - Compra por impulso: Os consumidores demonstram que no momento da compra o fator emocional sobrepõe-se à razão. Em muitos casos nota-se que nem sempre é necessário um motivo específico para adquirir um serviço.

Revista de Administração e Inovação, São Paulo, v. 10, n.1, p. 06-26, Jan./Mar. 2013. 
Rogers (1995) define as características mais importantes que as inovações devem ter para serem adotadas na visão dos consumidores. Dessas características, averiguou-se a presença de vantagem relativa, praticabilidade e observabilidade nos discursos formulados com base nas entrevistas realizadas. Tais características apresentam-se nas ideias centrais dos discursos seis “Troca por percepção de vantagem”, discurso sete "Experimentação" e discurso dez "Quantidade de inovações percebidas", respectivamente. O discurso seis esclareceu que os donos dos animais pensam em trocar o serviço já utilizado por um novo sempre que a novidade trouxer mais benefícios legítimos ao animal de estimação, essa percepção dos consumidores encaixou-se perfeitamente ao conceito de vantagem relativa de Rogers (1995). Já o discurso sete explicitou a vontade dos consumidores do mercado de Pet Shops em experimentar as inovações e, mostrando que quando a experiência se faz positiva, a adoção acontecerá consequentemente; o que remete à ideia de praticabilidade definida por este autor. Já o discurso dez se atrelou ao conceito de observabilidade quando os consumidores descrevem a necessidade de as inovações estarem visíveis nos Pet Shops, eles dizem que as novidades devem ser percebidas constantemente para que o estabelecimento não se torne obsoleto, o que diminuiria a vontade dos consumidores em frequentá-lo.

Além das definições de Rogers (1995), estabeleceu-se ainda ligação com as variáveis de comportamento do consumidor que influenciam as decisões de compra, essas variáveis dividem-se em três amplas categorias; diferenças individuais, influências ambientais e processos psicológicos. Destaca-se que a variável personalidade, pertencente à categoria de diferenças individuais, que contempla, além desta, as variáveis de recursos do consumidor, conhecimento, atitudes e motivação, esteve presente em todos os discursos coletados. Verificou-se que por se tratar de serviços relacionados aos animais de estimação, denominados pela maioria dos entrevistados nesta pesquisa membros de suas famílias, a diminuição da relevância de influências externas, já que os serviços desse mercado afetam diretamente a vida das pessoas, por refletirem o bem estar de seus animais. Verificou-se, por conseguinte, a existência de variáveis pertencentes à categoria de influências ambientais somente nos discursos três "Comodidade dos clientes". Destacando a presença da variável situação, já que os entrevistados discorrem sobre a facilidade de encontrar tudo o que precisam em um mesmo local, fato que estimula o consumo de inovações inclusive; e discurso oito "Preço", em que a variável classe social se faz presente, já que os consumidores deixam de adotar algumas inovações desse mercado por considerá-las fora de seu padrão de consumo, por conta do custo elevado. 
Por fim constatou-se até mesmo a presença da categoria de processos psicológicos, o grupo de processamento de informações apareceu nos discursos quatro "Confiança e segurança dos consumidores", nove "Satisfação advinda do atendimento" e onze "Qualidade". Em todos eles notou-se a necessidade dos consumidores em conhecerem de maneira mais aprofundada os serviços que irão adquirir, eles querem entender os processos e conhecer os funcionários, tanto os que realizarão os serviços de maneira direta quanto os que atendem o animal de maneira indireta. Como um recepcionista, por exemplo, que tem mais contato com o dono do animal, mas que também é visto como importante, já que será associado também ao atendimento do Pet Shop.

\section{CONSIDERAÇÕES FINAIS}

A pesquisa realizada revela indícios de que os consumidores do mercado de Pet Shops são extremamente exigentes e precisam ser estimulados à aquisição de novos serviços constantemente. Para tanto esses estabelecimentos devem estar atentos a seus hábitos de consumo, procurando trazer novidades que tragam primordialmente bem estar de seus animais de estimação.

O mercado de Pet Shops vem crescendo de maneira sustentável nos últimos quinze anos, fator que estimula a participação de novos entrantes no segmento. Esse crescimento gera uma busca constante por vantagem competitiva, o que favorece o surgimento de novas tecnologias e inovações oferecidas aos consumidores, que por sua vez percebem essas inovações de maneiras diferentes, mas se comportam de maneira relativamente semelhante na hora de adquirirem ou não essas inovações. O uso dos instrumentos de análise qualitativa do Discurso do Sujeito Coletivo possibilitou a identificação de três diferentes representações sociais alusivas às características que uma inovação em serviço no mercado de Pet Shop precisa ter para ser adotada, segundo a percepção dos consumidores; relacionou-se às ideias centrais dos discursos seis "Troca por percepção de vantagem", discurso sete "Experimentação" e discurso dez "Quantidade de inovações percebidas" os conceitos de vantagem relativa, praticabilidade e observabilidade, respectivamente. A análise realizada permitiu a observar algumas características que as inovações devem apresentar para serem adotadas, segundo a percepção dos indivíduos; concluindo-se que os consumidores adquirem um novo serviço quando o mesmo oferece uma vantagem perante o que o precede, quando essa inovação é visível para outros indivíduos ou quando o novo serviço pode ser experimentado e testado. Essas características estão relacionadas à adoção, que, segundo Rogers (1995), é o momento em que o consumidor decide utilizar a inovação.

Revista de Administração e Inovação, São Paulo, v. 10, n.1, p. 06-26, Jan./Mar. 2013. 
Contudo, a relação entre os discursos coletados e o conceito definido por Rogers (1995) demonstrou que o modelo escolhido não atendeu satisfatoriamente os objetivos previamente definidos para esta análise. Não foi possível relacionar todos os fatores relacionados pelo autor às ideias contidas nas entrevistas. Assim, verificou-se a necessidade da utilização desse modelo em paralelo a de outros autores. Tornando a pesquisa mais rica, já que a percepção dos consumidores entrevistados não se mostrou enquadrada somente nas características necessárias às inovações definidas por Rogers (1995), verificou-se a existência de outros fatores que influenciam a decisão de compra dos consumidores neste mercado.

Apuraram-se, também, algumas peculiaridades inerentes ao comportamento do consumidor que influenciam a decisão de compra, possibilitando a verificação da presença da variável personalidade, pertencente à categoria de diferenças individuais na totalidade dos discursos formulados. Fato este que destacou a importância dos valores individuais na tomada de decisão para aquisição de novos serviços neste mercado, as entrevistas realizadas demonstraram a preocupação dos consumidores em adquirir serviços de qualidade, que proporcionem bem estar aos seus animais de estimação principalmente, além de sentirem necessidade da transmissão de confiança por parte dos funcionários desse tipo de estabelecimento, já que somente assim se sentem seguros em deixar seus animais aos cuidados desses prestadores de serviços; tanto zelo se explica pela relação de afeto existente entre esses indivíduos e seus pets, fato constatado pelo fato de grande parte dos entrevistados considerar os animais como verdadeiros membros de suas famílias. Nesse sentido, verificou-se inclusive que estes consumidores estão mais exigentes para tomar a decisão de comprar ou não um novo serviço. Parte dessa tendência pode ser explicada pela crescente diversidade de serviços oferecidos nesse mercado, mas deve-se observar o fato de as entrevistas realizadas terem sugerido que a preocupação desses sujeitos em proporcionar bem estar aos seus animais é fato determinante no momento da aquisição de novos serviços.

A principal contribuição desse diagnóstico foi evidenciar que alguns consumidores dos serviços de Pet Shops entendem que as inovações desse mercado podem influenciar a aquisição de um novo serviço ou produto neste mercado.

\subsection{LIMITAÇÕES DO ESTUDO}

A execução desta pesquisa não buscou entender a realidade desse mercado, nem traçar o perfil dos consumidores pertencentes a ele. Mas sim colaborar com futuras pesquisas relacionadas 
ao tema, já que atualmente não se verifica muitos estudos elaborados que contemplem o comportamento dos consumidores de Pet Shops, os quais possuem enorme potencial de consumo, o que determina o contínuo e acelerado crescimento desse mercado. $\mathrm{O}$ método de pesquisa utilizado nesse trabalho identificou algumas características necessárias às inovações do mercado de Pet Shops para que sejam adotadas, na visão dos consumidores. Em relação à metodologia do Discurso do Sujeito Coletivo (DSC) é essencial destacar que esta não permite a generalização dos resultados obtidos. Pois o que foi constatado nesta pesquisa nem sempre é reflexo da realidade como um todo. A generalização neste caso não se aplica.

\subsection{RECOMENDAÇÕES PARA TRABALHOS FUTUROS}

Recomenda-se realizar novos estudos a respeito do tema, a fim identificar de forma mais aprofundada e objetiva os resultados apresentados nesse trabalho. As novas pesquisas podem ser feitas baseadas também em métodos qualitativos, na tentativa de identificar os tipos de consumidores existentes no mercado Pet, buscando entender os serviços que cada perfil de consumidor adquire. A realização dessa pesquisa pode ser utilizada para a formulação de uma pesquisa quantitativa, gerando resultados que realmente reflitam o mercado. Outra possível análise giraria em torno do grau de importância dedicado pelos consumidores desse mercado aos estabelecimentos que realizam ações de caridade com os animais, estabelecimentos que abrigam animais abandonados, doam filhotes que podem servir como guias para pessoas com deficiência visual, entre outras ações sociais, analisar se ações desse tipo estimulam o consumo nesses Pet Shops. Além disso, pode-se analisar quais inovações são vistas como benéficas aos animais e quais os consumidores consideram exageradas, verificando até que ponto as novidades desse mercado são vistas como positivas pelos consumidores.

Outro ponto que pode ser abordado é a qualidade dos serviços oferecidos nos Pet Shops que por conta da grande demanda, podem não conseguir oferecer serviços que atendam as expectativas dos consumidores. Nessa pesquisa o foco seria os próprios estabelecimentos, oferta e demanda dos mesmos, e alternativos para se diferenciarem nesse mercado amplo e em acelerado crescimento. Acredita-se que a atual pesquisa, por meio das entrevistas individuais realizadas, tenha contribuído para a identificação desses tópicos a serem analisados em futuras pesquisas a respeito do mercado Pet e seus consumidores.

Revista de Administração e Inovação, São Paulo, v. 10, n.1, p. 06-26, Jan./Mar. 2013. 


\section{REFERÊNCIAS}

Afuah, A. (2009) Strategic Innovation: New Game Strategies for Competitive Advantage. Business, v. 44, p. 91-116). Routledge.

Bessant, J. R.; Tidd, J. (2007) Innovation and Entrepreneurship. (Z. J. Pudlowski, Ed.) Innovation, v. 31, p. 2002. Wiley

Chesbrough, H. W. (2007). Business model innovation: it's not just about technology anymore. Strategy Leadership, 35(6), 12-17.

Collis, J.; Hussey, R. (2010) Business research: a practical guide for undergraduate and postgraduate students. Palgrave Macmillan.

Demo, P. (1995) Metodologia Cientifica Em Ciencias Sociais. Atlas.

Drucker, P. F. (2008) Inovação e espírito empreendedor (entrepreneurship): prática e princípios. São Paulo: Pioneira Thomson.

Fielding, N. G. (1999) The norm and the text: Denzin and Lincoln's handbooks of qualitative method. British Journal of Sociology, v. 50, n. 3, p. 525-534.

Frambach, R. T.; Schillewaert, N. (2002) Organizational innovation adoption: a multi-level framework of determinants and opportunities for future research. Journal of Business Research, $\mathrm{v}$. 55 , n. 2, p. 163-176.

Henriques, J. (2010) Gestão de Expectativas: A nova abordagem de marketing. YEN, Portugal.

Kotler, P.; Keller, K. (2009) Marketing management: Analysis, planning, and control. Organization, 2009. Prentice Hall.

Krishnan, M. S.; Prahalad, C. K. (2010) A Nova Era da Inovação Parte 1. Hsm management book summary $n^{\circ} 9$.

Lefevre, F.; Lefevre, A. M. C. (2006) O sujeito coletivo que fala. Interface Comunicação Saúde Educação, v. 10, n. 20, p. 517-524.

Revista de Administração e Inovação, São Paulo, v. 10, n.1, p. 06-26, Jan./Mar. 2013. 
Markides, C. (2006) Disruptive Innovation: In Need of Better Theory. Journal of Product Innovation Management, Blackwell Publishing Limited v. 23, n. 1, p. 19-25.

Oliva, F. L. Sobral, M. C.; Santos, S. A. D. (2011) Measuring the probability of innovation in technology-based companies. Journal of Manufacturing Technology Management, v. 22, n. 3, p. 365-383.

Peter, P. J. Churchill JR, G. A.; Brown, T. J. (1993). Caution in the Use of Difference Scores in Consumer Research. Journal of Consumer Research, v. 19, n. 4, p. 655-662. The University of Chicago Press.

Rigueira, M. (2012) Mercado brasileiro de produtos pet já é o segundo maior do mundo. Jornal o Estado de Minas, p.13.

Robertson, T.S., (1967). The Process of Innovation and the Diffusion of Innovation. Journal of Marketing, 31 (January), 14-19.

Rogers, E. M. (1995). Diffusion of innovations. (M. B. Salwen \& D. W. Stacks, Eds.). An integrated approach to communication theory and research (Vol. 65, p. 519). Free Press

Schumpeter, J. A. (2000) Entrepreneurship as innovation. In: R. Swedberg (Ed.); Entrepreneurship The Social Science View. p.51-75, Oxford University Press.

Severino, A. J. (2008) A pesquisa em educação: a abordagem crítico-dialética e suas implicações na formação do educador. Revista Contrapontos.

Shapiro, B. P. (1985) Rejuvenating the marketing mix. Harvard Business Review, v. 63, n. 5, p. 2834.

Sheth, J. N. Eshghi, A.; Krishnan, B. C. (2001) Privacy in the information age: stakeholders, interests and values. Harcourt.

Solomon, M. R. (1987) The Role of the Surrogate Consumer in Service Delivery. The Service Industries Journal, v. 7, n. 3, p. 292-307. 
Toledo, L. A; Zilber, M. A. (2009). Inovação e tecnologia: um estudo de suas singularidades. REVISTA PRETEXTO, 10(4), 9-30.

Toledo, L. A; Zilber, M. A. (2012). An analysis of the fallacy of taking apart technology and innovation. RAI Revista de Administração e Inovação, 9(1), 211-230.

Trivinos, A. (1997) Introdução à pesquisa em ciências sociais: a pesquisa qualitativa em educação. Filosofia, 33-41. Atlas

Vargas, E. R. D. (2008) Compras Governamentais e Inovação em Serviços de. ANPAD, p. 1-15.

Yoon, S. (2002) The antecedents and consequences of trust in online-purchase decisions. Journal of Interactive Marketing, v. 16, n. 2, p. 47-63. 


\title{
INNOVATION UNDER THE PET SHOPS MARKET
}

\begin{abstract}
The article aims to enhance some aspects of innovation that can influence the Brazil's Pet Shops buying marketing. The paper makes use of qualitative methodology based Collective Subject Discourse data analyses. Thus 12 discourse subjects are presented that illustrate the most relevant and cited aspects by respondents. Finally, discourse analysis has contributed to three different social representations that innovation can take a part in the Pet Shop market under the consumer perspective.
\end{abstract}

Keywords: Pet Shop; Innovation; DSC.

Data do recebimento do artigo: 29/06/2012

Data do aceite de publicação: 05/02/2013

Revista de Administração e Inovação, São Paulo, v. 10, n.1, p. 06-26, Jan./Mar. 2013. 